$\xi=-1$

\title{
A frequency reconfigurable antenna with Bluetooth, Wi-Fi and WLAN notch band characteristics
}

\author{
A Vamseekrishna ${ }^{1 *}$, B T P Madhav ${ }^{2}$ \\ ${ }^{1}$ Research Scholar, Department of ECE, Koneru Lakshmaiah Education Foundation, Vaddeswaram, AP, India \\ ${ }^{2}$ Professor, ALRC, Department of ECE, Koneru Lakshmaiah Education Foundation, Vaddeswaram, AP, India \\ *Corresponding author E-mail: vamseekrishna.a3@gmail.com
}

\begin{abstract}
A compact coplanar waveguide fed reconfigurable antenna with three notch bands are presented in this paper. Proposed antenna reconfigurability is acquired by placing bar6404 PIN diodes in the S-shaped ground plane in right to left mode and left to right mode. By switching the diode, reconfigurability achieved for three different operations. The substrate material for the proposed antenna is FR4 with dielectric constant 4.4 and loss tangent 0.02 . The overall dimension of the reconfigurable antenna is around $30 \times 26 \mathrm{~mm} 2$. It is being observed in this work for the cause of each individual slot on notch band characteristics. The measured gain for the designed reconfigurable antenna is quite stable at operating frequencies except notch bands. The proposed antenna is suitable for practical wideband applications with notching.
\end{abstract}

Keywords: coplanar waveguide, Reconfigurable antenna, PIN diode, S-shaped.

\section{Introduction}

Now days there is more attention on antennas with reconfigurable characteristics for modern wireless communication systems. Reconfigurability provides ability for the antennas to operate in the preferred frequency band and rejects the other bands. The reconfigurable antenna reduces the complexness of hardware and value of the system. Reconfigurable antennas area unit controlled by PIN/varactor diodes and MEMS [1-4]. For a frequencyreconfigurable monopole antenna with three switchable operating modes: UWB, band-notched UWB and dual band radiator, the reconfigurability for the three radiating modes is achieved by controlling the bias voltage of $\mathrm{p}-\mathrm{i}-\mathrm{n}$ diodes and single antenna can be exploited for the three operating modes without changing the physical dimensions of the structure [5-8] and the reconfigurability of a planar monopole antenna with triple notched band in the band between $3.1 \mathrm{GHz}$ to $10.6 \mathrm{GHz}$ is achieved using two Cshaped slot and a rectangular slot (open-ended quarter-wavelength slot) to filter the frequency bands in the ultra-wide band [9-12]. To achieve reconfigurable band-notch characteristics the two switches are used in main radiators to activate/deactivate the slots on them, providing reconfigurable band-notch characteristics for WLAN [13-16]. To miniaturize and achieve reconfigurability, PIN/varactor diodes are introduced in the design. Further, by adding PIN diodes strategically placed on the CPW loaded with SSRRs, the band stop behavior of the overall structure can be reconfigured to a bandpass behavior [17-18]. Another way to introduce the reconfigurable technique to design a continuously tunable dual notched-band UWB antenna is by cutting two u-shaped slots in the radiation patch to generate dual band-notched characteristics at the central frequency at $3 \mathrm{GHz}$ and $5 \mathrm{GHz}$, respectively and two varactor diodes are placed in the middle of the u-shaped slots which control the notched-band frequency [19-20].

The novelty of this communication lies in the follow aspects.

1) For wireless systems such as mobile internet devices and smart phones to access the wireless spectrum of WLAN, WiMAX, and $\mathrm{UWB}$, a frequency reconfigurable antenna is employed.

2) The reconfigurable filtering antenna not only realizes multiband operation, but also achieves miniaturization of the RF front end.

3) The WLAN frequency response is produced by bandpass filters; it has the potential to be applied to other wireless systems, such as WiMAX, Bluetooth, and Global Navigation Satellite System by choosing appropriate filter structure. In this paper we proposed reconfigurable antenna with three notch bands. The reconfigurability achieved by switching the diodes D1, D2 in S-shaped ground plane.

\section{Antenna Geometry and Design}

The geometry of the proposed model is shown in Fig:1a. The reconfigurability achieved by placing $S$-shaped structure in ground plane shown in Fig:1b. The geometry of S-shaped structure is shown in Fig:1c. The antenna is printed on FR4 substrate. In top view of the antenna placed two $\mathrm{C}$-shaped elements with radius of $9.2 \mathrm{~mm}$ and $4 \mathrm{~mm}$. The thickness of the antenna is $0.8 \mathrm{~mm}$. The dimension of the reconfigurable antenna is around $30 \times 26 \mathrm{~mm} 2$. The antenna is fed to the Co-Planar-Waveguide. The width of the feedline $1.5 \mathrm{~mm}$. The antenna parameters are given in Table1.CPW feed allows the realization of series as well as shunt connections on one side substrate. The advantages of using CPW feed are 


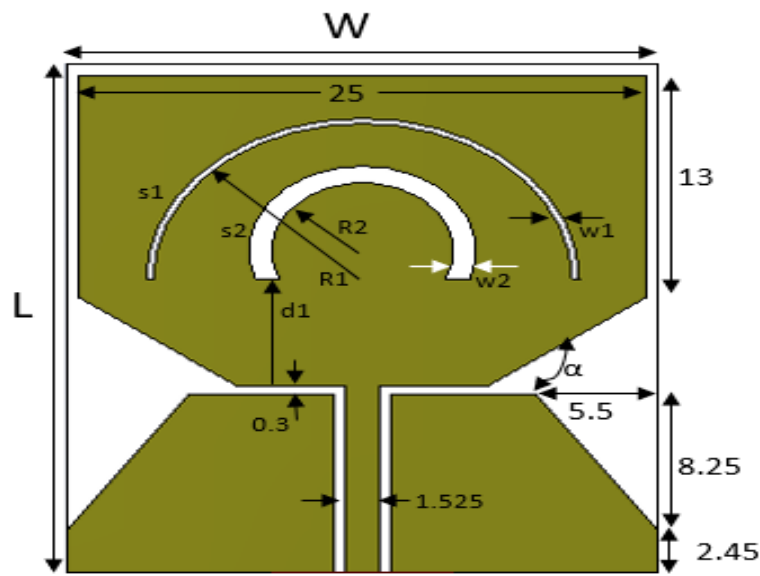

(a)

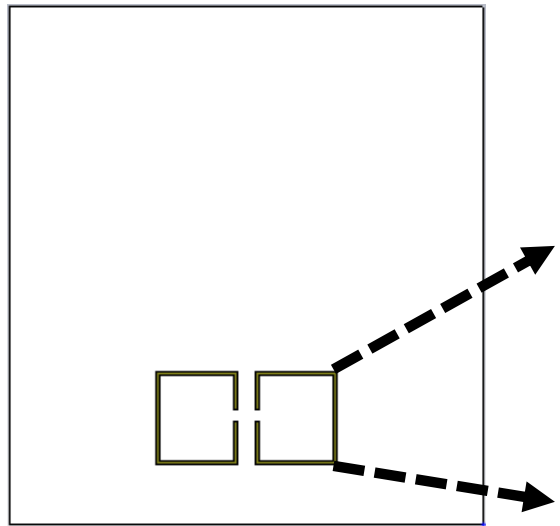

(b)

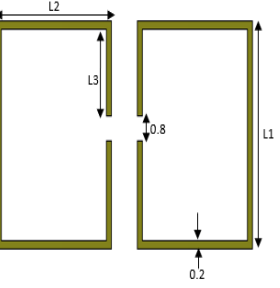

(c)

Fig 1: (a)Antenna Top view, (b)Bottom view, (c) S-shaped structure

reduction in size, simple structure, ease of impedance matching, makes integration of active devices easier. The reason for using low dielectric substrate is to reduce radiation loss

\begin{tabular}{|c|c|c|c|}
\hline $\begin{array}{c}\text { Antenna } \\
\text { parameter }\end{array}$ & $\begin{array}{c}\text { Dimensions } \\
(\mathrm{mm})\end{array}$ & $\begin{array}{c}\text { Antenna } \\
\text { parameter }\end{array}$ & $\begin{array}{c}\text { Dimensions } \\
(\mathrm{mm})\end{array}$ \\
\hline Alpha & 0.6 & $\mathrm{~L} 1$ & 5.2 \\
\hline $\mathrm{L}$ & 30 & $\mathrm{~L} 2$ & 1.8 \\
\hline $\mathrm{W}$ & 26 & $\mathrm{~L} 3$ & 2.3 \\
\hline $\mathrm{d} 1$ & 6 & $\mathrm{R} 1$ & 9.2 \\
\hline $\mathrm{d} 2$ & & $\mathrm{R} 2$ & 4 \\
\hline $\mathrm{H}$ & 0.8 & $\mathrm{t}$ & 0.8 \\
\hline $\mathrm{K}$ & 4 & $\mathrm{w} 1$ & 0.3 \\
\hline $\mathrm{w} 2$ & 1 & $\mathrm{w} 3$ & 0.5 \\
\hline $\mathrm{wf}$ & 1.5 & $\mathrm{wp}$ & 25 \\
\hline
\end{tabular}

In the ground plane of the proposed antenna placed diode D1 in left to right(LR) mode it is shown in Fig:2(a). Then placed diode D2 in right to left (RL) mode. By making diodes D1 and D2 on and off obtained the reconfigurable characteristics.

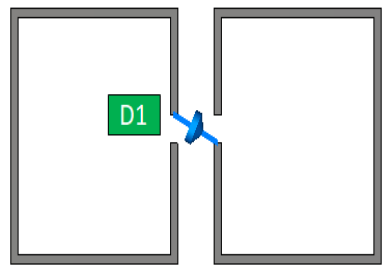

(a)

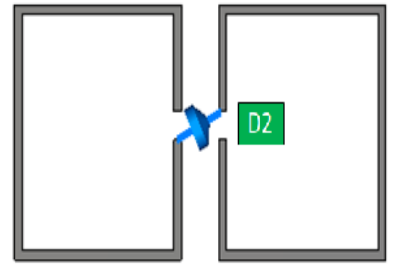

(b)

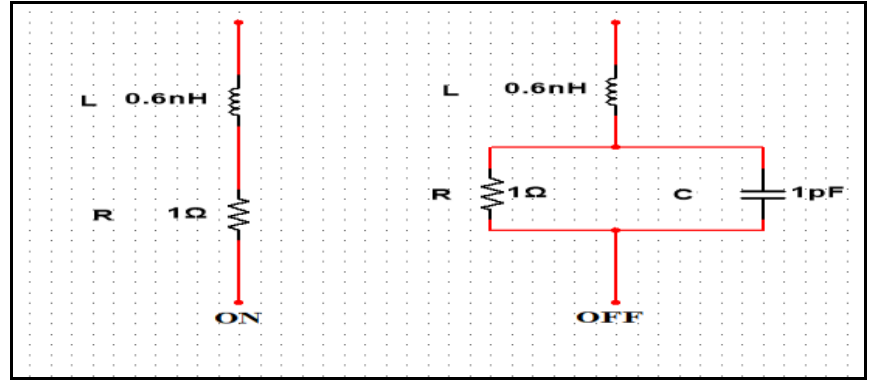

(c)

Fig 2: S-shaped ground plane with PIN Diode in LR mode(b)in RL mode(c)Diode equivalent structure

The diode equivalent circuit is shown in Fig:2(c). When the diode is in ON condition the elements $\mathrm{L}$ and Rare placed in series combination. When the diode is in off condition the elements $\mathrm{R}$ and $\mathrm{C}$ are connected in parallel combination. By applying proper biasing make the diode on and off.

\section{Design of CPW Feeding}

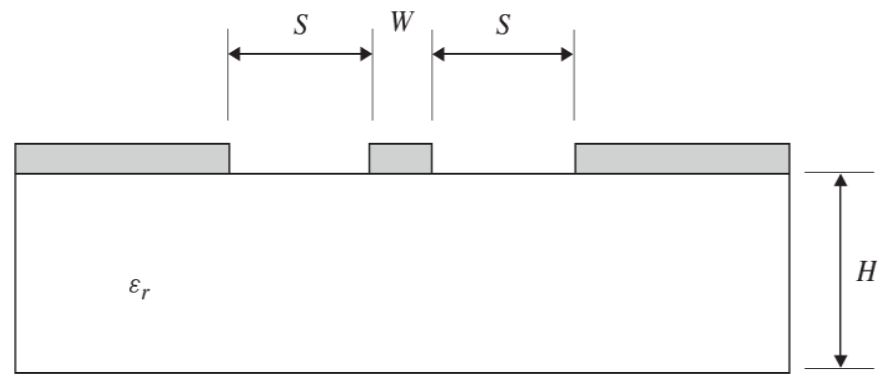

Fig3: Cross section of a classic coplanar waveguide structure

The effective permittivity of CPW structure is given by

Effective permittivity $=\varepsilon_{r e}=\frac{c}{c^{2}}=\frac{\varepsilon_{r}+1}{2}$

Phase velocity $=v_{p h}=\frac{c}{\sqrt{\varepsilon_{r e}}}=c \sqrt{\frac{2}{\varepsilon_{r+1}}}$

Characteristic impedance $=z_{o}=\frac{1}{C v_{p h}}=\frac{1}{c \sqrt{\varepsilon_{r e}}} \frac{1}{c^{2}}$

Relation of elliptic integral, of the first kind and its

complement $k^{\prime}\left(k_{1}\right)=k^{\prime}\left(k_{1}\right)$ with $_{1}^{\prime}=\sqrt{1-k_{1}^{2}}$

Argument of the elliptic integrals $=k_{1}=\frac{a}{b}=\frac{s}{s+2 w}$

Capacitance $c_{2}=2 \varepsilon_{0} \varepsilon_{r} \frac{k\left(k_{1}\right)}{k^{\prime}\left(k_{1}\right)} ; c_{1}=2 \varepsilon_{0} \frac{k\left(k_{1}\right)}{k^{\prime}\left(k_{1}\right)}$

Total capacitance $=c=c_{1}+c_{2}=2 \varepsilon_{0}\left(\varepsilon_{r}+1\right) \frac{k\left(k_{1}\right)}{k^{\prime}\left(k_{1}\right)}$

$\frac{k(k)}{k^{\prime}(k)}=\frac{\pi}{\ln \left[2\left(1+\sqrt{k^{\prime}}\right) /(1-\sqrt{k})\right]}$ for $0 \leq k \leq 0.707$

$\frac{k(k)}{k^{\prime}(k)}=\frac{1}{\pi} \ln [2(1+\sqrt{k}) /(1-\sqrt{k})]$ for $0.707 \leq k \leq 1$ 


\section{Results and Discussions}

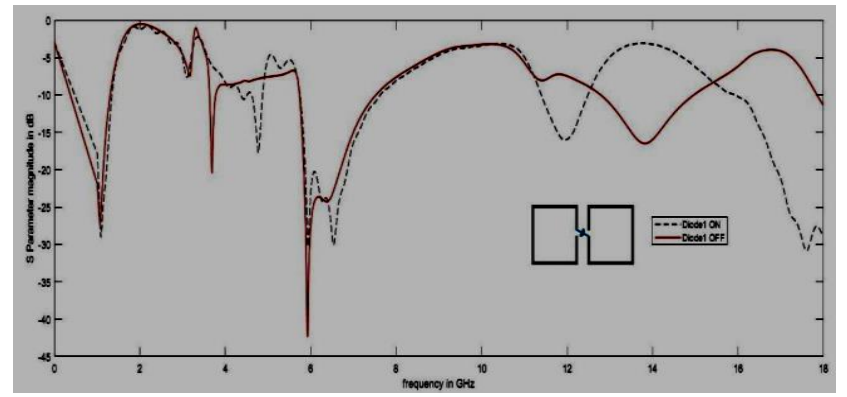

\begin{tabular}{|c|c|}
\hline Diode state & Operating band \\
\hline D1 ON & $5.4-5.8 \mathrm{GHz}$ \\
\hline D1 OFF & $3.7-3.9 \mathrm{GHz}$ \\
\hline
\end{tabular}

Fig 4: Reflection coefficient when diode D1 is connected in LR mode

The simulated result for reflection coefficient when diode D1 is connected in left to right to the ground plane of the antenna. When the Diode D1 is on antenna operated in the range $5.4 \mathrm{GHz}$ to 5.8 GHz.It is shown in Fig-3 in dotted lines. When diode D1 off antenna operated between 3.7 to $3.9 \mathrm{GHz}$. It is shown in straight line in Fig 4. By switching the Diode D1, achieved the reconfigurable characteristics.

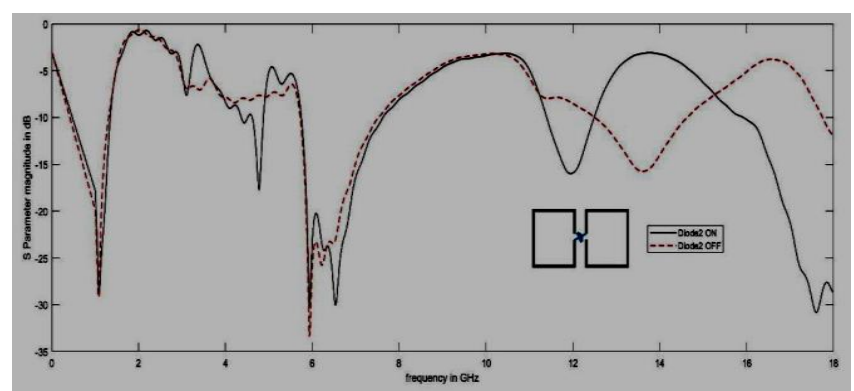

\begin{tabular}{|c|c|}
\hline Diode state & Operating band \\
\hline D1 ON & $4.8-5 \mathrm{GHz}$ \\
\hline D1 OFF & $5.8-6.3 \mathrm{GHz}$ \\
\hline
\end{tabular}

Fig 5: Reflection coefficient when diode D2 is connected in RL mode

The simulated result for reflection coefficient when diode D2 is connected in right to left to the ground plane of the antenna. When DiodeD2 is on operated in the range $4.8 \mathrm{GHz}$ to $5 \mathrm{GHz}$.It is shown in Fig-4 in straight lines. When diode D2 off it operated between 5.8 to $6.3 \mathrm{GHz}$.It is shown in dotted line in Fig 5. By switching the Diode D2 achieved the reconfigurable characteristics.

For different frequencies the surface current distribution of proposed antenna is analysed notch frequencies $3.7 \mathrm{GHz}$ and $5.4 \mathrm{GHz}$ the current distribution is shown in Fig 6a, b. The surface current is allocated invariantly over the entire antenna. In the ground plane at S-shaped structure a strong current distribution is occurred and at slot $\mathrm{S} 1$ also a strong current distribution occurs.
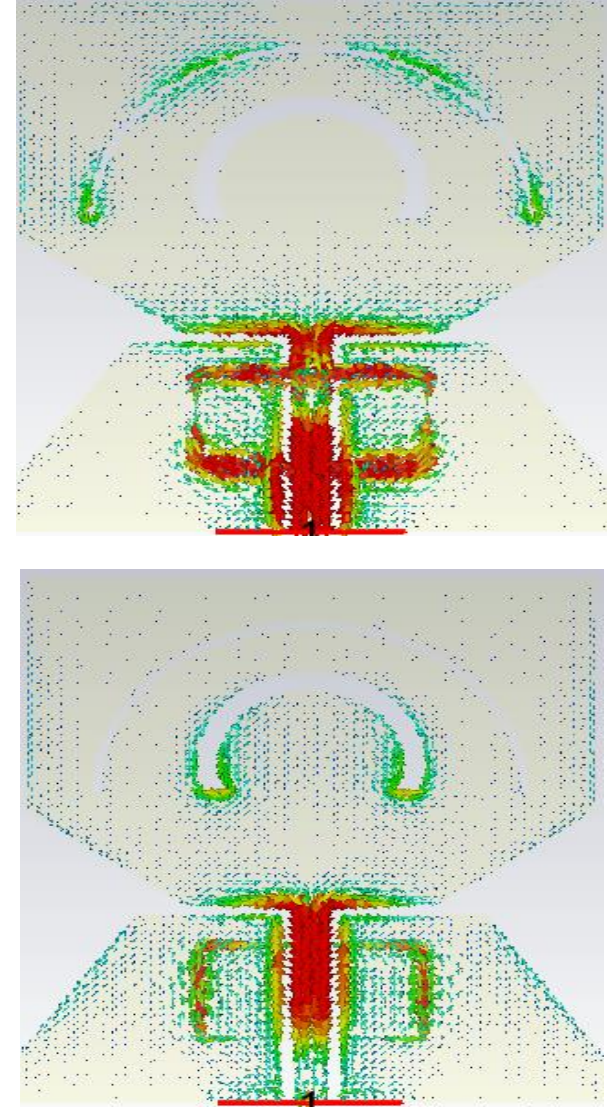

Fig 6a, b: Current distribution at $3.7 \mathrm{GHz}$ and $5.4 \mathrm{GHz}$

The two dimensional and three-dimensional radiation patterns of the reconfigurable antenna at different frequencies are shown in Fig 7, 8. Omni directional radiation pattern observed at lower and higher frequency bands. Antenna is producing gain more than $5 \mathrm{~dB}$ in the operating band and negative values in notch bands. The frequency vs gain plot is shown in Fig 9.
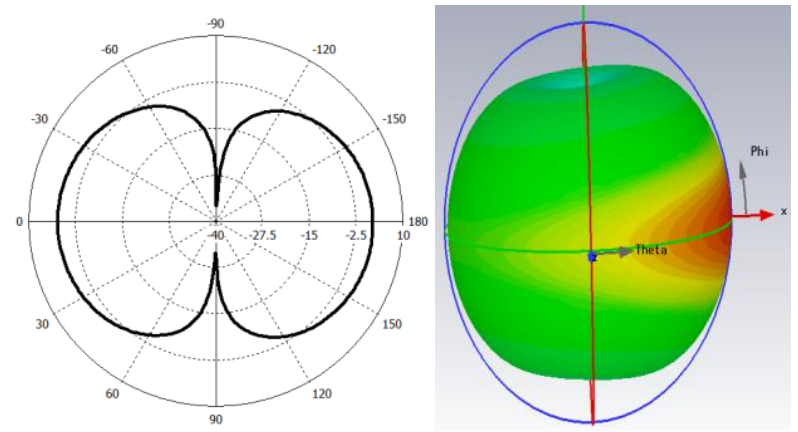

Fig 7: Radiation pattern of antenna at $3.7 \mathrm{GHz}$

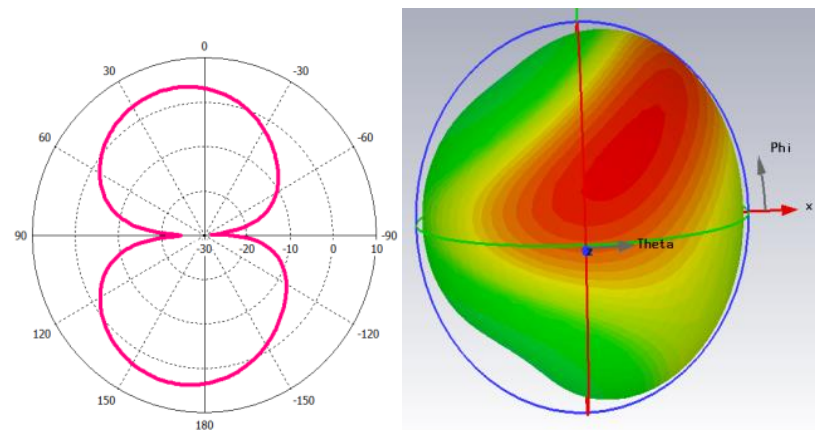

Fig 8: Radiation pattern of antenna at $5.4 \mathrm{GHz}$ 


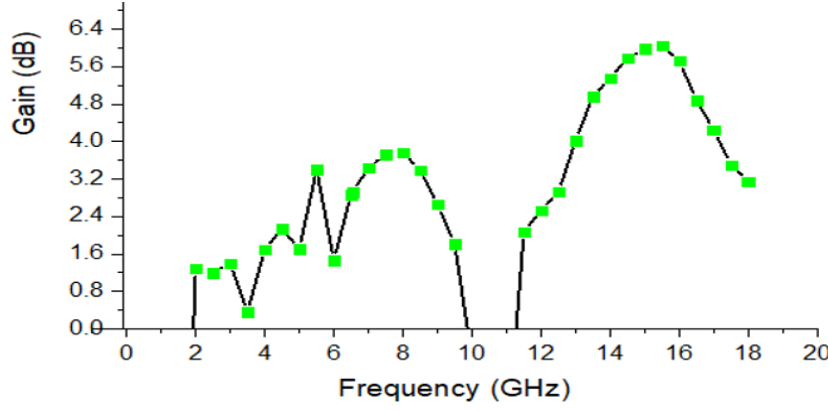

Fig 9: Frequency vs Gain plot

\section{Conclusion}

A switchable reconfigurable antenna is designed and analysed with monopole configuration in this paper. Antenna with S-shaped structure demonstrated, and diodes are placed in that structure. By making diode on and off conditions fine-tune the notch bands in this work. All the antenna parameters with respect to switching are analysed and presented. The radiation characteristics and corresponding directivity and gain parameters are presented and analysed. The designed model is simple in structure and easy to fabricate and it is useful for UWB applications.

\section{Acknowledgements}

The authors feel happy to acknowledge department of ECE, ECM and management of KLU for the support during this work.Dr.B.T.P. Madhav likes to thank DST for their support through grant ECR/2016/000569 and SR/FST/ETI-316/2012.

\section{References}

[1] Zhang X-Q, Jiao Y-C, Wang W-H, Compact wide tri-band slot antenna for WLAN/WiMAX applications, Electron Letters, Vol 48, No 2, 2012, pp 64-65.

[2] Harish Kaza, Thanneru Kartheek, Vidyullatha Lakshmi Kaza, Sreeramineni Prasanth, K S Sanjay Chandra Sikakollu, Maneesh Thammishetti, Aluvala Srinivas, K V L Bhavani, Novel Printed Monopole Trapezoidal Notch Antenna with S-Band Rejection, Journal of Theoretical and Applied Information Technology, ISSN: 1992-8645, Vol 76, No 1, 2015, Pp 42-49.

[3] P.Lakshmikanth, Kh Takeshore, Printed Log Periodic dipole antenna with Notched filter at $2.45 \mathrm{GHz}$ Frequency for wireless communication applications, Journal of Engineering and Applied Sciences, ISSN: 1816-949X, Vol 10, Issue 3, Aug-2015, pp 40-44.

[4] D S Ram Kiran, Novel compact asymmetrical fractal aperture Notch band antenna, Leonardo Electronic Journal of Practices and Technologies, ISSN 1583-1078, Vol 27, Issue 2, December 2015, pp 1-12.

[5] M L S N S Lakshmi, Habibulla Khan, Novel Sequential Rotated 2x2 Array Notched Circular Patch Antenna, Journal of Engineering Science and Technology Review, ISSN: 1791-2377, Vol 8, issue 4, Dec-2015, pp 73-77.

[6] M. V. Reddiah Babu, Sarat K. Kotamraju, Compact Serrated Notch Band MIMO Antenna for UWB Applications, ARPN Journal of Engineering and Applied Sciences, ISSN 1819-6608, VOL. 11, NO. 7, APRIL 2016, pp 4358-4369.

[7] D S Ramkiran, Kankara Narasimha Reddy, Shaik Shabbeer, Priyanshi Jain, Saggurthi Sowmya, Coplanar Wave Guide Fed Dua Band Notched MIMO Antenna, International Journal of Electrical and Computer Engineering (IJECE), ISSN: 2088-8708, Vol. 6, No. 4, August 2016, pp. 1732-1741.

[8] Y. S. V. Raman, Analysis of Circularly Polarized Notch Band Antenna With DGS, ARPN Journal of Engineering and Applied Sciences, ISSN: 1819-6608, Vol. 11, No. 17, September 2016.
[9] M Vamsi Krishna Chaitanya Reddy, M Venkateswara Rao, C Mohan Krishna, P Chandan Raj, G Jaya, Quad Band Filtenna using Split Ring Resonators to Notch Unwanted Frequencies in Medical Application Bands, Journal of Theoretical and Applied Information Technology, ISSN: 1992-8645, Vol 95, No 9, May17, pp 2070-2077.

[10] T. V. Rama Krishna, B. Sindhu, Liquid Crystal Polymer based Optimized Notch Band Monopole Antenna, Rasayan Journal of Chemistry, ISSN: 0974-1496, Vol 10, No 3, Jul-2017, pp 799. 806.

[11] D.S. Ram Kiran, V. Alekhya, An Asymmetric Liquid Crystal Polymer Based Fractal Slotted UWB Monopole Antenna with Notch Band Characteristics, Rasayan Journal of Chemistry, ISSN: 0974-1496, Vol 10, No 3, Jul-2017, pp 852-860.

[12] Prakash B L, Sai Parimala B, Sravya T, Anil Kumar T, Dual Band Notch MIMO antenna with meander slot and DGS for ultra-wideband applications, ARPN Journal of Engineering and Applied Sciences, ISSN: 1819-6608, Vol 12, Issue 15, 2017, pp 4494-4501.

[13] Allam Vamsee Krishna, Planar Switchable Notch Band Antenna with DGS for UWB Applications, Lecture Notes in Electrical Engineering, ISSN: 1876-1100, Vol 434, 2017, pp 509-518.

[14] D.S. Ramkiran, P. Siddaiah, Band-Notched Circular Serrated Wideband Antenna, Lecture Notes in Electrical Engineering, ISSN: 1876-1100, Vol 434, 2017, pp 555-563.

[15] S.S. Mohan Reddy, P. Mallikarjuna Rao, Design and Analysis of Circular Notch Band DGS Monopole Antenna, Lecture Notes in Electrical Engineering, ISSN: 1876-1100, Vol 434, 2017, pp 409-417.

[16] A Sudeepa, V Manikanth, P Sai Bharathi, P Lakshmi Srikanth, A N Meena Kumari, Dielectric Resonator Integrated UWB Antenna with Dual Band Notch Characteristics, International Journal of Pure and Applied Mathematics, ISSN: 1311-8080, Volume 115, No. 7, 2017, pp 375-379.

[17] Kosuru Murthy, Kodidasu Umakantham, Korlapati Satyanarayana Murthy, Reconfigurable Notch Band Monopole Slot Antenna for WLAN/IEEE-802.11n Applications, International Journal of Intelligent Engineering and Systems, ISSN: 2185-3118, Vol 10, No 6, Oct-2017, pp 166-173.

[18] Vamseekrishna Allam, Defected Ground Structure Switchable Notch Band Antenna for UWB Applications, Smart Innovation, Systems and Technologies, Vol 77, pp 139-145, 2018.

[19] U Ramya, M Ajay Babu, M Venkateswara Rao, Double Notch Reconfigurable Monopole Antenna with Stub Loaded DGS, International Journal of Pure and Applied Mathematics, Vol 117 No. 18, 2017, pp 97-103

[20] T. Anusha, T. V. Ramakrishna, A. N. Meena Kumari, DualBand-Notched CPW-Fed Antennas with WiMAX/WLAN Rejection for UWB Communication, Lecture Notes in Electrical Engineering, ISSN: 1876-1100, Vol 471, 2018, pp 559-570. 